\title{
Program Berkelanjutan Membantu Mitra Organik Jaya dengan Usaha Media Tanam Organik di Kabupaten Padang Pariaman
}

\author{
Ratna Aisuwarya $^{1)}$, Sinta Silvia ${ }^{2)}$, Monika Rianti Helmi ${ }^{3)}$, Afriyanti Dwi Kartika ${ }^{4)}$, Melia \\ Amalia', Wahyu Budiman')
}

\author{
Fakultas Teknologi Informasi ${ }^{1,4,5,6)}$, Fakultas Teknik ${ }^{2)}$, \\ Fakultas Matematika dan Ilmu Pengetahuan Alam ${ }^{3)}$ \\ Universitas Andalas
}

Email: aisuwarya@it.unand.ac.id

\begin{abstract}
ABSTRAK
Mitra Organik Jaya mulai merintis usaha media tanam dan pupuk organik untuk mencoba bersaing terutama di tengah situasi pandemi yang menuntut agar pelaku usaha agar bisa menyesuaikan diri dengan media usaha digital market.Mitra Organik Jaya merupakan usaha skala rumahan yang dirintis sejak pertengahan tahun 2020. Karena keterbatasan ilmu dan pengetahuan dalam membuat media tanam serta pupuk organik tersebut. Sehingga solusi dari permasalah tersebut adalah pelatihan pembuatan pupuk dan media tanam organik sesuai dengan standar baku dengan uji kelayakan produk berdasarkan kandungannya. Tujuan yang ingin dicapai dari kegiatan pengabdian masyarakat ini adalah meningkatkan kemampuan mitra khususnya pada usaha home industry bidang media tanam organik di kabupaten Padang Pariaman. Program pengembangan yang akan disepakati dengan mitra adalah : Desain produk, merek, dan standarisasi uji produk, izin usaha, pemasaran produk berbasis digital market. Semua program ini dilakukan dalam kurun waktu 3 tahun. Pada tahap awal pelaksanaannya di tahun 2020, kegiatan ini telah menghasilkan luaran berupa desain kemasan produk dan merek, serta ijin usaha bagi mitra.
\end{abstract}

Kata kunci: Pupuk Organik, Digital Market, Pengembangan Usaha

\begin{abstract}
Organic Jaya has started planting media and organic fertilizer to compete, especially during a pandemic situation that requires business actors to adapt to the digital business media market. Mitra Organic Jaya is a home-scale business initiated in mid-2020. Due to the limitations of science and knowledge in making planting media and organic fertilizers. So that the solution to this problem is training in the manufacture of organic fertilizers and planting media following standards with product feasibility tests based on their content. The community service activity's purpose is to increase partners' ability, especially in the home industry business in organic planting media in Padang Pariaman district. The development programs agreed with partners are Product design, branding, and standardization of product testing, business licenses, digital market-based product marketing. All of these programs are carried out within three years. In the early stages of its implementation in 2020, this activity has produced outputs in the form of product and brand packaging designs and business licenses for partners.
\end{abstract}

Keywords: Organic Fertilizer, Digital Market, Business Development 


\section{Pendahuluan}

Makin tingginya pelaku bisnis pertanian organik membuat permintaan pupuk organik makin meningkat (Anwar, 2019), (Cundari, 2019). Hal ini membuka sebuah peluang bisnis pupuk organik yang menjanjikan. Usaha pupuk organik memang menjadi salah satu usaha yang akhir-akhir ini menjadi trend. Pupuk organik banyak dicari dan permintaannya sangat besar dipasaran. Meningkatnya kebutuhan pupuk organik tidak berimbang dengan jumlah pelaku bisnis pupuk organik yang masih terbilang rendah. Hal ini membuka celah peluang bisnis yang menjanjikan. Sehingga Mitra Organik Jaya mulai merintis usaha media tanam dan pupuk organik untuk mencoba bersaing terutama di tengah situasi pandemi yang menuntut agar pelaku usaha agar bisa menyesuaikan diri dengan media usaha digital market.

Mitra Organik Jaya merupakan usaha skala rumahan yang dirintis sejak pertengahan tahun 2020. Berawal dari situasi pandemi Covid-19 yang melanda Dunia, khususnya Indonesia, yang mengakibatkan terhentinya sektor ekonomi di beberapa bidang. Awalnya pimpinan mitra memiliki profesi sebagai tukang ojek pangkalan, namun karena situasi pandemi membuat usaha ini terhenti. Kemudian, dilanjutkan dengan kurir pengantaran barang sesuai dengan permintaan pelanggan. Belakangan permintaan pengantaran pupuk organik dan media tanam lainnya meningkat pesat, akibat perubahan kebiasaan kerja yang beralih menjadi WFH (Work From Home). Sehingga konsumen pupuk organik meningkat seiring dengan meningkatnya trend pertanian organik. Peluang ini dimanfaatkan oleh mitra untuk memulai usaha media tanam dan pupuk organik. Untuk merintis usaha ini, mitra memulai dengan usaha reseller produk yang sudah ada. Karena keterbatasan ilmu dan pengetahuan dalam membuat media tanam serta pupuk organik tersebut.

\section{Tinjauan Pustaka}

Pupuk kimia berperan untuk memperkaya mineral (hara), (Sutrisno, 2019), yang diperlukan tanaman namun pemakaiannya yang tidak bijaksana menimbulkan efek buruk terhadap lahan pertanian seperti penurunan kesuburan, tanah kehilangan daya ikat alamiahnya, tandus, dan miskin bahan organik, (Hananingtyas, 2020). Oleh karena itu tren meningkatnya kesadaran masyarakat yang tinggi memunculkan teknik pertanian modern dengan gaya organik. Cara pertanian yang seperti ini memang sangat bagus dimana lebih mengedepankan kualitas tanaman dengan penggunaan bahan-bahan alami seperti halnya pupuk organik.

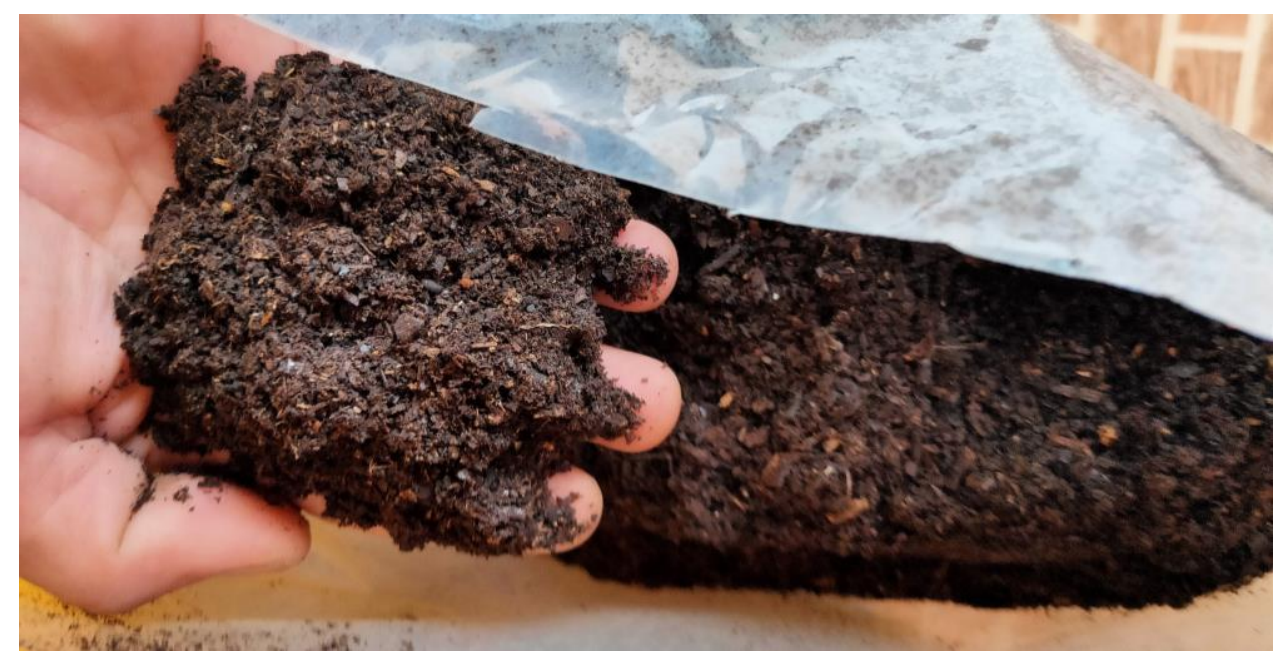

Gambar 1. Pupuk Kompos Organik 


\section{Metodologi Penelitian}

Metode dan tahapan pelaksanaan kegiatan pengabdian masyarakat ini terbagi menjadi dua tahap, yaitu tahap pembinaan dan pendampingan. Adapun tahapan pertama berupa pembinaan dengan urutan pelaksanaan sebagai berikut : (1). Persiapan, (2). Pelaksanaan Kegiatan, (3). Evaluasi, (4). Pembuatan Laporan.

Berikut pada Tabel 1 adalah rancangan jadwal kegiatan untuk pelaksaan kegiatan pengabdian masyarakat ini, mulai saat survei dilakukan sampai selesainya semua laporan kegiatan yang sudah dilakukan.

Tabel 1. Tahapan Solusi Untuk Atasi Permasalahan Mitra

\begin{tabular}{|c|c|c|c|c|c|c|c|c|c|}
\hline \multirow{2}{*}{ No } & \multirow{2}{*}{ Aktivitas } & \multicolumn{8}{|c|}{ Minggu } \\
\hline & & 1 & 2 & 3 & 4 & 5 & 6 & 7 & 8 \\
\hline 1. & $\begin{array}{l}\text { Analisis kelemahan dan permasalahan } \\
\text { usaha mitra }\end{array}$ & $*$ & $*$ & & & & & & \\
\hline 2. & $\begin{array}{l}\text { Pertemuan tim penyusunan rencana } \\
\text { kegiatan 1-3 tahun }\end{array}$ & & $*$ & $*$ & & & & & \\
\hline 3. & $\begin{array}{l}\text { Pertemuan I pembahasan rencana } \\
\text { pengembangan 1-3 tahun dengan mitra }\end{array}$ & & & $*$ & $*$ & & & & \\
\hline 4. & $\begin{array}{l}\text { Pertemuan II penyepakatan } \\
\text { pengembangan } 1-3 \text { tahun dengan mitra }\end{array}$ & & & & & $*$ & $*$ & & \\
\hline 5. & Seminar hasil & & & & & & & $*$ & \\
\hline 6. & Laporan akhir & & & & & & & & $*$ \\
\hline
\end{tabular}

Media pertemuan untuk pelaksanaan kegiatan pengabdian masyarakat ini diantaranya :

Pertemuan langsung ke lokasi mitra dengan menerapkan protokol kesehatan covid-19 untuk survey lokasi, menganalisis kelemahan dan permasalahan usaha mitra.

Pertemuan secara daring melalui media komunikasi zoom. Dilakukan untuk forum diskusi tim penyusun rencana kegiatan 1-3 tahun. Kemudian menyepakati usulan pengembangan tersebut dengan mitra usaha.

Untuk mencapai tujuan yang telah dirumuskan sebelumnya, pelaksanaan pengabdian masyarakat ini dilakukan dalam beberapa langkah yang melibatkan metode penelitian lapangan berupa wawancara, penelitian pustaka, diskusi dan demonstrasi/pelatihan. Evaluasi dilakukan untuk menjamin keberlanjutan program.

\subsection{Metode Evaluasi Pelaksanaan Kegiatan 2020}

Pelaksanaan kegiatan pada tahun 2020 berupa Pertemuan langsung ke lokasi mitra dengan menerapkan protokol kesehatan covid-19 untuk survey lokasi, menganalisis kelemahan dan permasalahan usaha mitra. Pertemuan juga dilakukan secara daring melalui media komunikasi zoom. Dilakukan untuk forum diskusi tim penyusun rencana kegiatan 1-3 tahun. Evaluasi dilakukan terhadap rencana kegiatan yang telah disusun, untuk dapat diimplementasikan pada tahun 2021.

\subsection{Keberlanjutan Program Pengembangan pada 2-3 Tahun ke Depan}

Keberlanjutan program pengembangan pada tahun pelaksanaan (tahun satu - tahun 3) dapat diuraikan sebagai berikut :

Tahun 1 -2 merupakan tahap pembinaan dengan sasaran : pelatihan pembuatan pupuk dan media tanam organik, pembuatan desain produk, merek, dan uji kelayakan produk. Keberhasilan tahap satu ini di evaluasi melalui output yang dihasilkan.

Tahun 3 merupakan tahap pendampingan dengan sasaran : pengurusan ijin usaha, manajemen dan pemasaran. Keberhasilan tahap dua ini di evaluasi melalui keberhasilan mitra dalam memperoleh ijin usaha dan mendapatkan hasil penjualan melalui digital market. 


\section{Hasil dan Pembahasan}

Program pengembangan yang akan disepakati dengan mitra adalah : Desain produk, merek, dan standarisasi uji produk, izin usaha, pemasaran produk berbasis digital market. Semua program ini dilakukan dalam kurun waktu 3 tahun.

\subsection{Rencana Program Pengembangan Usaha Mitra Tahun 2021-2023}

Tabel 2. Peta Jalan Program Pengembangan Usaha Mitra Tahun 2021-2023

\begin{tabular}{|c|c|c|c|c|c|}
\hline \multirow{2}{*}{ No. } & \multirow{2}{*}{ Program } & \multicolumn{2}{|c|}{ Pembinaan } & \multirow{2}{*}{$\frac{\text { Pendampingan }}{2023}$} & \multirow{2}{*}{ Luaran } \\
\hline & & 2021 & 2022 & & \\
\hline 1. & Pembinaan produksi & $*$ & $*$ & & Usaha dengan produksi sendiri \\
\hline 2. & $\begin{array}{l}\text { Pembinaan produksi dan } \\
\text { pengemasan produk }\end{array}$ & & $*$ & & $\begin{array}{l}\text { Usaha dengan merek dan kemasan } \\
\text { produk }\end{array}$ \\
\hline 3. & Pengembangan produk & & $*$ & & Usaha dengan pengembangan produk \\
\hline 4. & $\begin{array}{l}\text { Peningkatan manajemen } \\
\text { pemasaran produk }\end{array}$ & & $*$ & $*$ & $\begin{array}{l}\text { Usaha dengan tata kelola, target } \\
\text { kinerja yang efisien }\end{array}$ \\
\hline 5. & $\begin{array}{l}\text { Penetapan izin usaha dan } \\
\text { pengembangan } \\
\text { pemasaran dan promosi }\end{array}$ & & & $*$ & $\begin{array}{l}\text { Usaha dengan perijinan dan } \\
\text { pengembangan manajemen pemasaran } \\
\text { yang efisien }\end{array}$ \\
\hline
\end{tabular}

\subsection{Luaran yang Telah Dicapai}

Luaran yang telah dicapai pada kegiatan pengabdian masyarakat ini adalah :

1. Desain Merek dan Kemasan Produk.

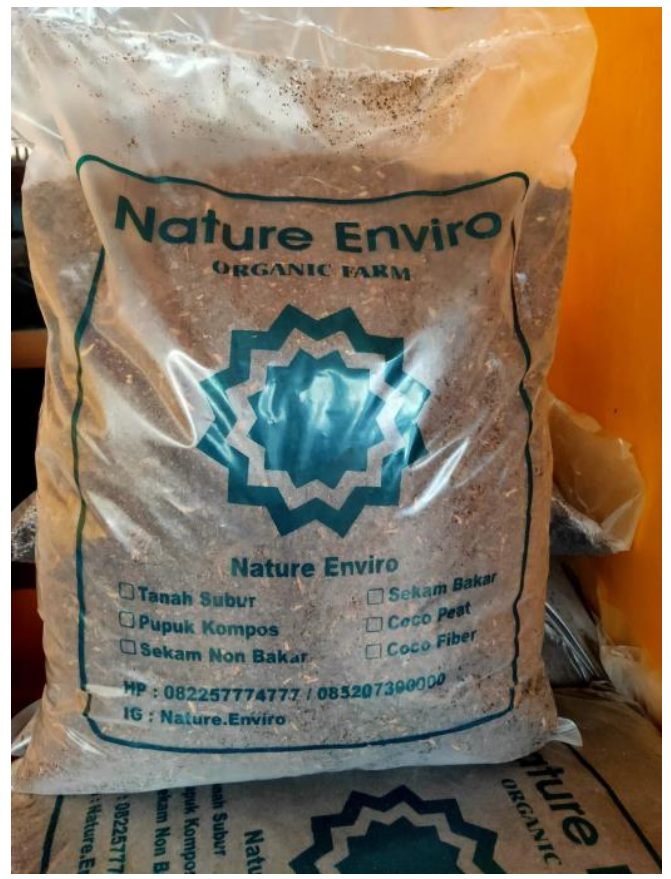

Gambar 2. Desain Kemasan Produk 
2. Izin Usaha.(Nomor Induk Berusaha (NIB) dan Izin Usaha Mikro Kecil (IUMK))

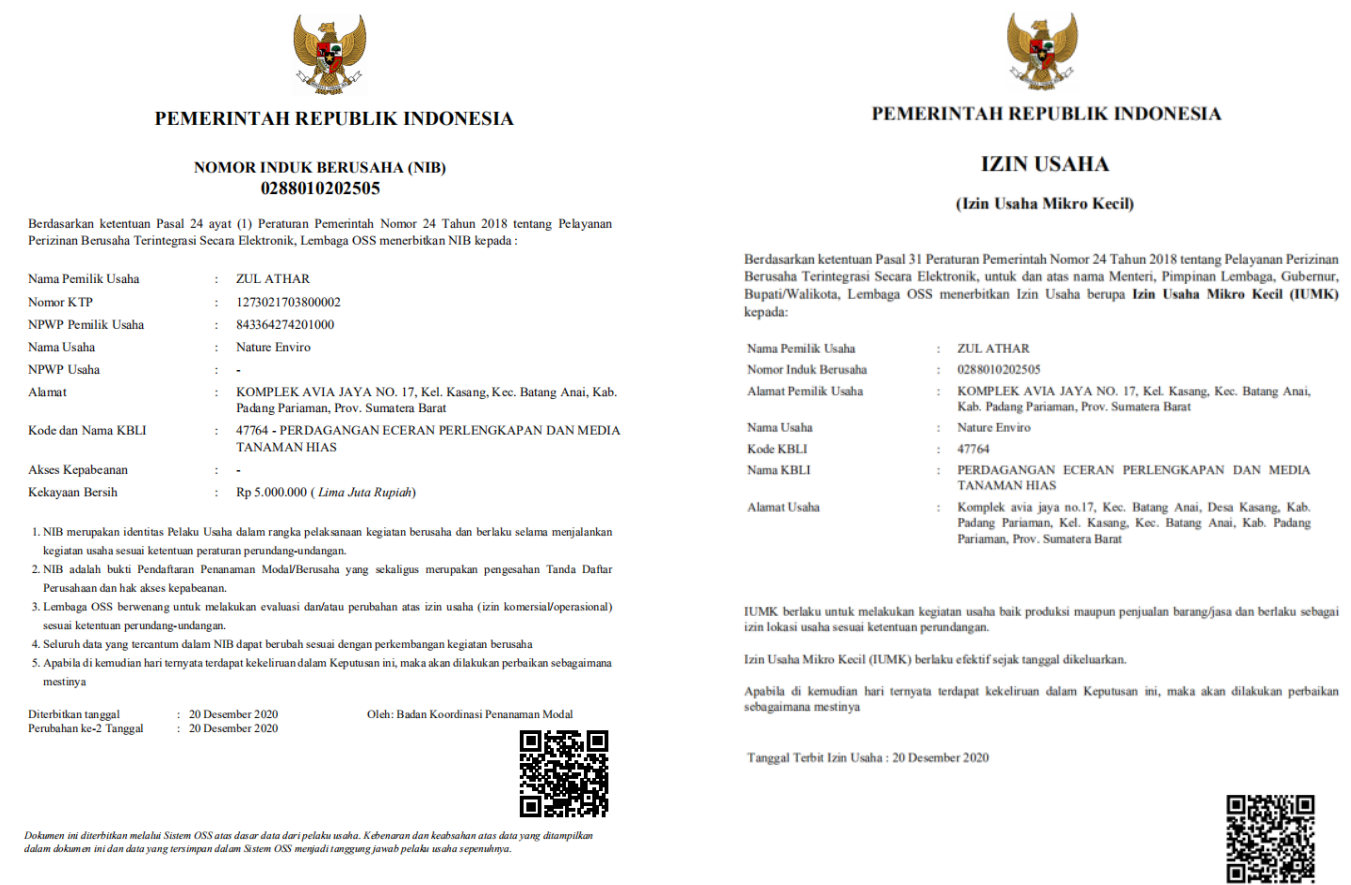

Gambar 3. Surat Keterangan Ijin Usaha dan Nomor Induk Berusaha

3. Toko Online pada Digital Market Place.

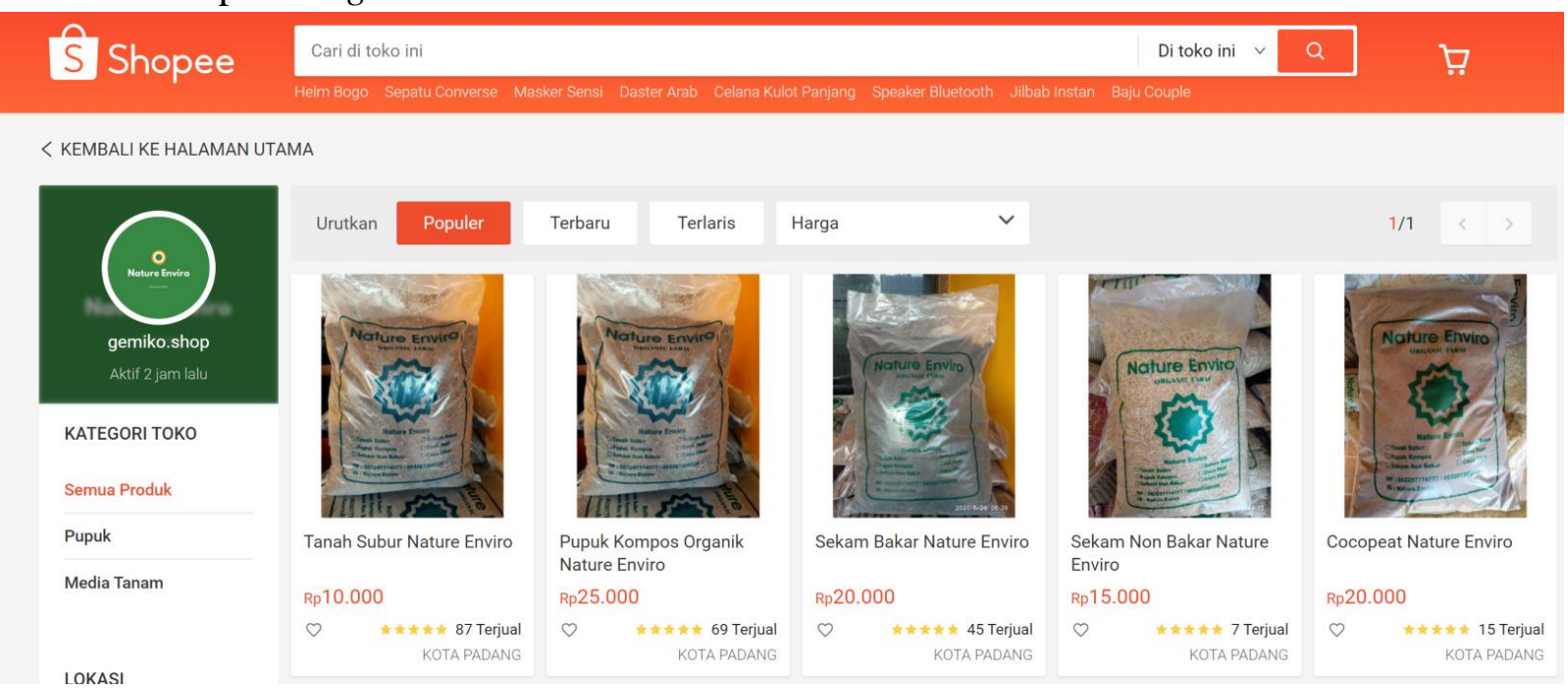

Gambar 4. Toko Online pada Digital Market Place 
4. Publikasi pada Media Massa.

\section{MinangkabauNews}
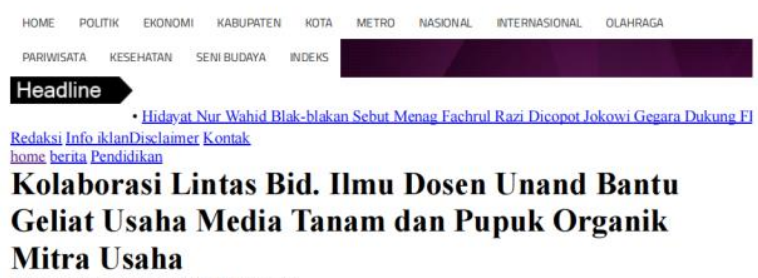

Gambar 5. Berita Media Massa Online

\section{Kesimpulan dan Saran} berikut :

Berdasarkan hasil kegiatan pengabdian yang telah dilakukan dapat diambil kesimpulan sebagai

1. Telah disepakati langkah-langkah penyelesaian permasalahan mitra yang akan dilaksanakan dalam beberapa tahapan sesuai dengan prioritas masalah. Tahapan ini akan dilaksanakan dalam rentang waktu 3 tahun. Tahap pembinaan dilakukan pada tahun 1 dan 2. Setelah dilakukan evaluasi, maka pada tahun ke 3 akan dilakukan tahap pendampingan mitra.

2. Telah dihasilkan desain merek dan desain kemasan produk Mitra dengan merek "Nature Enviro".

3. Produk mitra telah dipasarkan melalui digital market place Shopee dengan beberapa variasi jenis produk.

4. Mitra sudah didaftarkan dan telah memperoleh Nomor Induk Berusaha (NIB) dan Izin Usaha Mikro Kecil (IUMK).

\section{Ucapan Terima Kasih}

Penulis ingin mengucapkan terima kasih kepada LPPM Universitas Andalas yang telah membiayai kegiatan Pengabdian Kepada Masyarakat ini serta kepada Mitra Organik Jaya yang telah berkenan menjadi Mitra Pengabdian Kepada Masyarakat.

\section{Daftar Pustaka}

Anwar, M. C., Rudijanto I.W, H., Triyantoro, B., \& Wibowo, G. M. (2019). Pembuatan Pupuk Kompos Dengan Komposter Dalam Pemanfaatan Sampah Di Desa Bringin Kecamatan Bringin Kabupaten Semarang. Jurnal LINK, 15(1), 47-49.

Cundari, L., Arita, S., Komariah, L. N., Agustina, T. E., \& Bahrin, D. (2019). Pelatihan dan pendampingan pengolahan sampah organik menjadi pupuk kompos di desa burai. Jurnal 
Teknik Kimia, 25(1), 5-12.

Hananingtyas Izza. (2020). Implementasi Pengelolaan Sampah Rumah Tangga Melalui Pelatihan Pembuatan Pupuk Kompos., Jurnal As-Syifa, Jurnal pengabdian dan Pemberdayaan Kesehatan Masyarakat, Vol 1 no 2.

Utomo Budi.(2018). Evaluasi pembuatan Kompos Organik Dengan Menggunakan Metode Hot Composting., e-journals.Ummul.ac.id Volume 2 nomor 01.Veronika N, Dhora A, dan Wahyuni S. (2019).

Warjoto, R. E., Canti, M., \& Hartanti, A. T. (2018). Metode komposting takakura untuk pengolahan sampah organik rumah tangga di cisauk, tangerang. Jurnal Perkotaan, 10(2), 76-90.

Yuliananda, S., Utomo, P. P., \& Golddin, R. M. (2019). Pemanfaatan sampah organik menjadi pupuk kompos cair dengan menggunakan komposter sederhana. Jurnal Abdikarya : Jurnal Karya Pengabdian Dosen Dan Mahasisw, 3(2), 159-165. 